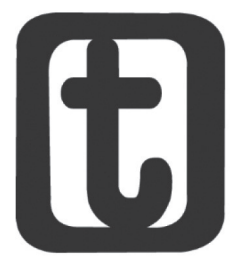

\title{
SOBRE O ESTADO, O PODER POLÍTICO E O ESTADO DEPENDENTE'
}

\author{
About State, Political Power and the Dependant State
}

Jaime Sebastian Osorio*

\begin{abstract}
RESUMO
Neste artigo se estabelecem elementos que determinam e definem o Estado e o poder político em geral, intervindo em discussões e propostas relevantes em suas caracterizações. São enfatizados dois pontos em particular: a relação Estado/ sociedade civil e a distinção entre Estado e aparato de Estado, perspectiva esta última de vital importância para definir o espaço teórico e explicar a emergência, potencialidades e limitações dos chamados governos populares na América Latina no seio de Estados capitalistas. Ao final do texto são formuladas de maneira resumida algumas características do Estado dependente.
\end{abstract}

\section{PALAVRAS-CHAVE}

Estado/sociedade civil; Poder político; Aparato de Estado; Estado dependente.

\section{ABSTRACT}

At the onset of the 21st Century, the State is being questioned. This essay lays out some items that determine and define the State, and Political Power in general, intervening in the discussions and proposals that are relevant in their characterizations. Emphasis is made on two aspects in particular: the relationship between State/Civil Society, and the distinction between State and State Apparatus. This last perspective is vital in order to define the theoretical realm that explains the emergency, the potencialities and limitations of the so called Popular Governments in Latin America, within Capitalist States. At the end of the essay, there is a brief framing of some of the characteristics of the Dependant State.

1 Tradução: Fernando Correa Prado, Maíra Machado Bichir e Diógenes Moura Breda. Supervisão de tradução: Carla Cecilia Campos Ferreira.

* Docente do Departamento de Relações Sociais da Universidad Autonoma do México (UAM, Ciudad de México, México). Endereço: Xochimilco Prol. Canal de Miramontes 3855, Ex de San Juan de Dios, 14387 Ciudad de México, CDMX, México. E-mail: <josorio@correo.xoc.uam.mx>. 


\section{PALAVRAS-CHAVE}

State/Civil Society; Political Power; State Apparatus; Dependant State.

Submetido em: 18/10/2017

Aceito em: 14/11/2017

\section{INTRODUÇÃO}

O Estado do início do século XXI encontra-se interpelado. A partir de distintas correntes e diversos problemas, o Estado volta a ser discutido, pondo em cheque sua condição de classe, sua centralidade em termos de poder, seu papel estratégico nas transformações da sociedade, sua persistência em meio a globalização, seus limites, seu acesso através do aparato do Estado para construir "vias democráticas ao socialismo”, suas contradições e sua crise.

Tudo que se diga e como se caracterize o Estado têm consequências diretas na política, na (in)definição de uma estratégia diante do poder, na ideia de sua transformação e na organização. Daí a importância e a necessidade de analisá-lo.

No texto a seguir, abordaremos alguns pontos fundamentais da relação Estado-poder político-revolução. Isso implica estabelecer limites. Ampliar a noção de Estado não significa enfrentá-lo em qualquer recanto da vida social. Não porque estendamos a noção de poder avançamos em radicalizar a política.

Ao final do texto, incluímos algumas notas obre as particularidades do Estado dependente, aquele que se faz presente na região. Aparecem novas determinações que se integram aos problemas abordados inicialmente.

\section{SOBRE O ESTADO E O PODER POLÍTICO}

Ao destacar suas determinações fundamentais, definimos o Estado como a condensação de relações de poder político e de domínio, as quais possuem uma dimensão que produz sentido de comunidade. Estas relações - fundamentalmente de classe, mas que não são alheias às relações de raça e de gênero - atravessam de diversas formas e em distintas direções todo o emaranhado da organização social. No entanto, tais relações possuem núcleos particulares de condensação. Ou seja, o Estado é violência e está atravessado por ela. Mas essa violência se condensa em leis, em espaços que ameaçam seu exercício, quando não se apresenta como uma prática 
aberta e visível. O Estado também produz marcas com sentido de comunidade, como os relatos que conformaram a nação, nas respostas a desastres, ou em imaginários de igualdade.

O Estado é a condensação das correlações de forças. Se diversas classes sociais (e outros grupos) atuam e se desenvolvem na sociedade, todas elas buscam alcançar seus interesses. Em diversos graus, o Estado tem a particularidade de assumir demandas e posições de todas as classes, frações e setores. Porém, assume-as com a condição de que há classes que detêm o poder político e outras não. Desta forma, muitos interesses sociais adquirem expressão na vida em comum, mas com limitações estabelecidas pelos interesses dos grupos sociais dominantes.

Para as classes sociais, conservar o poder político significa contar com a força social para organizar a vida em comum. Este não é um assunto irrelevante, porque implica criar um redemoinho na vida em comum, ao redor do qual fundamentalmente tudo gira, permitindo assim que os projetos e interesses dos que detêm o poder político prevaleçam mais do queabsorvereassumir posições einteresses de outras classes.

Os assalariados podem reivindicar empregos ou melhores salários. E é possível que alcançem estes objetivos em tempos e períodos específicos. Porém, permanecerão em um contexto em que a condição do trabalho assalariado se mantém. E isso é parte dos interesses das outras classes, as que dominam.

$\mathrm{Na}$ medida em que estas relações sociais e de força se naturalizam, o Estado pode se projetar como uma entidade que expressa os interesses da sociedade como um todo.

O Estado é o centro do poder político porque é nele que se condensa a força social que organiza a vida em comum. Sem Estado não seria possível dar forma a nenhum projeto e interesse de classe, e tampouco organizar a vida de outros seres humanos de maneira duradoura. Essa centralidade converte o Estado no centro de qualquer projeto político que queira modificar e transformar as relações que subjazem a organização da vida em comum e que a tornem possível. Não existem, nesse sentido, atalhos que permitam eludir o Estado².

$2 \mathrm{~A}$ formulação que afirma o contrário e que adquiriu maior visibilidade na região em tempos recentes está no livro de John Holloway (2002). 
A centralização do poder político no Estado não impede sua projeção ao espaço social como um todo, repercutindo na forma como este espaço se recria e se produz. As relações estatais têm a capacidade de se projetar sobre todas as novas dimensões da vida social na atualidade, tais como o espaço criado pela internet e seus dispositivos, os casamentos homoafetivos ou a "barriga de aluguel" para a gestação assistida.

Do ponto de vista dos problemas que a transformação da ordem social atual deve enfrentar, a centralização do poder político no Estado capitalista implica que, necessariamente, em algum momento dos enfrentamentos sociais, as relações de força e suas coisificações centralizadas devem ser destruídas.

Isto implica compreender as particularidades do Estado capitalista, compreender que não estamos, por exemplo, diante de um Estado feudal, uma entidade atomizada e descentralizada em diversos núcleos de poder, possibilitando sua destruição por etapas, a exemplo do que ocorreu com a longa marcha de Mao Tsé-Tung na China.

O Estado capitalista se expande, mas está formado por um feixe de relações de poder político que exigem condensação e centralização ${ }^{3}$ Se buscássemos alguma imagem para exemplificar o que afirmamos, não recorreríamos à imagem de uma rede de pescadores, com seus quadrados homogêneos, mas a uma teia de aranha, com raios abertos a todo o espaço, mas que partem e se condensam em um centro. ${ }^{4}$

As dimensões das relações sociais que constituem o Estado têm pesos constitutivos diferenciados. As relações de poder e domínio que definem as formas e modos de organização da vida em comum são mais determinantes que a dimensão de tais relações enquanto criação de sentido de comunidade. Por isso, ainda que esta última dimensão seja enfraquecida, isso não implica uma diluição do Estado. ${ }^{5}$ No máximo ocorrerá uma mudança na forma

3 Por isso é equivocada a ideia de "desintegração" ou de "fragmentação" do Estado capitalista. Ver ROUX (2010).

4 Este é um dos motivos que explicam a centralização da organização política.

5 Somente uma leitura que sobrevalorize a dimensão de comunidade do Estado, relegando e subvalorizando as relações de poder político e domínio, pode sustentar uma posição como a anterior. Ver Ávalos Tenorio (2010). 
de governo, segundo a terminologia clássica, onde as dimensões do autoritarismo prevalecerão sobre as consensuais.

\section{A FETICHIZAÇÃO DO ESTADO}

Se algo caracteriza o Estado capitalista é a fetichização das relações de poder e domínio, o que impede que essas relações apareçam tal como são, e ocorra a reconstrução da ficção de um mundo de homens livres e iguais, ao mesmo tempo em que o Estado aumenta sua presença como uma entidade abstrata. Com isso, a burguesia encontra solução para um problema nada menor: sua promessa civilizatória de construir um mundo de homens livres e iguais.

Esta fetichização tem sua origem no fato de que na sociedade capitalista o dinheiro opera como forma do valor, permitindo que os produtos do trabalho de produtores privados e independentes só possam ser trocados por este meio. Trata-se de uma entidade abstrata (o que é uma nota, senão um pedaço de papel? O que é um cartão de crédito, senão um pedaço de plástico?) que ofusca as relações entre seres humanos e a lógica do valor que busca valorizar-se, impondo-se e dominando as relações entre os membros da sociedade.

Da mesma forma que o dinheiro, expressão da forma-valor, o Estado também se constitui como uma abstração, fetichizada, que se sobrepõe à sociedade e que pareceria romper com a atomização e separação de seus membros, criando um imaginário fictício de comunidade ${ }^{6}$.

Com o desenvolvimento do capitalismo, as atividades econômicas ganham espaço e presença na vida social. Mas a lógica do capital projeta esta presença crescente como autonomia da economia em relação à política, processo que é reforçado quando essas dimensões dão origem a disciplinas cada vez mais especializadas, onde o imaginário de um mundo de homens livres e iguais se recria e o indivíduo é colocado como a unidade básica a partir da qual se deve pensar a vida em sociedade.

6 Existem diversos estudos sobre o Estado que utilizam a forma-valor como elemento chave para sua compreensão. Ver, por exemplo, Álvaro Garcia Linera (2015). A forma dinheiro - diz García Linera - tem "[... ] a mesma lógica constitutiva que a forma Estado [...]", pelo que "[...] a lógica das formas do valor e do fetichismo das mercadorias [...] [são] a profunda lógica que também dá lugar a forma Estado e a sua fetichização" (GARCIA LINERA, 2015, p. 150-152). Ver, também, Gerardo Ávalos Tenorio (2015). 
Para uma economia determinada, não política, os homens que levam a cabo as trocas nos mercado são livres, agem aparentemente sem coação alguma, enquanto que na política, não econômica, ${ }^{7}$ são indivíduos iguais os que dão vida ao Estado como autoridade que protege a comunidade (segundo o relato contratualista), ficção que ganha força com a reconfiguração do cidadão e com a ampliação do sufrágio, procedimento em que cada indivíduo deposita um só voto, igual aos dos outros cidadãos, sem importar se uns são donos de empresas e outros são somente empregados assalariados das mesmas empresas. ${ }^{8}$

A ruptura entre economia e política faz parecer que as relações entre exploração e o exercício do poder e do domínio desapareçam. Porém, as relações sociais de exploração, mesmo fetichizadas pelo dinheiro, operam na criação de comunidade. Para o caso do dinheiro, García Linera afirma que “[...] permite o intercâmbio de produtos [... ] e, com isso, facilita a realização do valor de uso dos produtos concretos do trabalho humano, (o que) se plasma na [...] satisfação de necessidades de outros seres humanos". E acrescenta, “[...] não há dúvida de que está é uma função de sociabilidade, de comunidade" (GARCÍA LINERA, 2015, p. 151).

Já vimos, por outro lado, que as relações de poder e domínio do Estado, em sua forma fetichizada, projetam-se também como gestoras de comunidade (ilusória): cada cabeça, um voto, igualdade política, tomada de decisões sobre a vida em comum.

Tudo isso nos permite entender por que o Estado não aparece como condensação de poder político e domínio, pois, a partir da fetichização de suas relações econômico/políticas, a exploração, o poder e o domínio desaparecem, favorecendo justamente a construção de imaginários de comunidade. Em outras palavras, há um sentido de comunidade que provém justamente do funcionamento das relações de poder e domínio, na medida em que aparecem como seu contrário, favorecendo "[...] o mundo encantado, invertido e colocado de cabeça para baixo [...]” (MARX, 1973, p. 768) que o capital exige. Por sua vez, pela via das políticas sociais, o Estado

7 Retomo aqui a ideia de Ávalos Tenorio (2007, p. 57).

8 Trabalhamos esse tema no Anexo "A ruptura entre economia e política no mundo do capital" publicado no livro O Estado no centro da mundialização (OSORIO, 2014). 
é um grande criador de consensos, o que, somado ao anterior, questiona a ideia do Estado somente como poder e coerção.

Se, um dia após outro, e apesar de que o sentido de comunidade se debilite, reproduzem-se as relações sociais que organizam a relação capital-trabalho; a produção e apropriação de maisvalia se mantêm e se reproduz; persiste a exploração; o capital continua encontrando espaços de valorização; então deveremos reconhecer que nessa vida social continuam imperando uma organização específica da vida em comum que beneficia algumas classes e prejudica outras. Em outras palavras, continuam operando e reproduzindo-se relações de poder político e de domínio, ou seja, o Estado continua existindo. E é muito provável que suas formas (como se exerce o poder) continuem se modificando.

As relações sociais de produção imperantes no capitalismo permitem, por sua vez, que estas relações se reproduzam cotidianamente, tendo consequências na reprodução das relações de poder e de domínio e em sua capacidade de criar sentido de comunidade. Na medida em que o salário cobre o equivalente de um dia do valor da força de trabalho9, é necessário que o assalariado volte a se apresentar para trabalhar no dia seguinte, para poder apropriar-se de um novo dia de salário e de meios de vida. E isso tem como correlato o incremento do capital. Dessa maneira, a própria reprodução do capital reproduz, diariamente, trabalhadores e capitalistas, os quais se encontram dia após dia dispostos a realizar contratos de trabalho.

Assim, existe uma espécie de imanência na vida social capitalista que aponta à reprodução das relações sociais de produção, das classes sociais e das relações de poder e domínio. Enquanto essas condições aparecem como uma ordem natural: "assim se trabalha e assim se resolve a subsistência", as relações de poder político e de domínio do Estado não precisam tornar-se explícitas e operam como uma espécie de determinação geral para que a rotina dos contratos capital/trabalho e da produção e reprodução do capital ocorram com fluidez e sem perturbações. Isto permite

9 É uma hipótese que não se verifica no capitalismo dependente e tampouco para diversos setores de trabalhadores do mundo desenvolvido. 
que o Estado capitalista não apareça comprometido no dia a dia com a exploração, nem com o fortalecimento e com a reprodução do capital, o qual aprofunda sua imagem de entidade neutra em termos classistas e situada acima da sociedade.

\section{ESTADO E SOCIEDADE CIVIL: ASSIMILAÇÕES E DISTINÇÕES}

Afirmar que o Estado é o centro do poder político não implica desconhecer que, no domínio e na gestação de sentido de comunidade, operam outras relações e entidades, as instituições da sociedade civil, escolas, igrejas, meios de comunicação (tradicionais e as novas redes sociais da Internet), entre outras, criadoras de valores e interpretações da vida social.

Estas instituições, articuladas com o Estado, dão vida ao sistema de dominação, entendido como o conjunto de relações e processos por meio das quais as classes dominantes procuram perpetuar a ordem social imperante, internalizando seus valores e pretendendo, com maior ou menor êxito, que a sociedade e o mundo sejam interpretados de acordo com seus pontos de vista. Em outras palavras, as relações que outorgam sentido de comunidade, e que emanam do próprio Estado, são reforçadas pela ação de entidades que não são o Estado em sentido estrito. ${ }^{10}$

Para destacar o importante papel daquelas instituições na dominação não é preciso assumi-las como instâncias do Estado, como ocorre na proposta de Louis Althusser e de Nicos Poulantzas, que as denominam "aparelhos ideológicos do Estado", ${ }^{11}$ ou na versão neogramsciana que conduz ao conceito de "Estado ampliado" de Gramsci, que afirma que o "Estado é igual à sociedade política mais sociedade civil, hegemonia revestida de coerção". ${ }^{13}$

Estas formulações criam mais problemas teóricos e políticos que os que pretendem resolver. Em primeiro lugar, porque diluem a centralidade do Estado em matéria de poder político; segundo, porque fazem perder a especificidade do Estado e do poder político.

10 Em situações específicas, o aparato de Estado pode integrá-las, como ocorre quando os meios de comunicação estão subordinados diretamente ao governo. Mas isso não é a norma, pelo menos na democracia liberal.

11 Ver Louis Althusser (1974) e Nicos Poulantzas (1979).

12 Ver Lucio Oliver (2009).

13 Ver Antonio Gramsci (1975). 
Se assumirmos que o poder político repousa no Estado e nas instituições da sociedade civil mencionadas, abre-se espaço para que qualquer alteração de forças relevante no âmbito das instituições seja interpretado como transformações em matéria de poder, geralmente assumidos como perda de poder político pelas classes dominantes e como acumulação de poder pelas classes dominadas.

A extensão do conceito de Estado à sociedade civil supõe que as relações de poder político estão distribuídas homogeneamente entre o Estado e a sociedade civil, motivo pelo qual avançar na sociedade civil traz implícita a ideia de que, por aquele meio, está se resolvendo o problema do poder. Em outras palavras, assume-se que os avanços no sentido da hegemonia ideológica (direção) são sinônimos de poder político.

No entanto, se algo caracteriza as instituições da sociedade civil, sob formas democráticas, é que nelas são permitidos espaços e posições contrárias aos interesses dos que dominam. Não é raro que se permita a circulação de uma imprensa opositora, nem que surjam programas de rádio críticos aos projetos hegemônicos, ou que haja cátedras e matérias contrárias ao ponto de vista das classes dominantes no âmbito das instituições de ensino ${ }^{14}$. Esta permissividade não ocorre, porém, no nível do aparato de Estado, por mais que a conformação de governos populares no século XXI na América Latina apareça como algo rotineiro. Pelo contrário, na história política, e não somente regional, são processos excepcionais. E será menos possível ainda no próprio nível do Estado, como posições entre classes antagônicas ${ }^{15}$.

A ideia implícita nestas interpretações é a de que alcançar o poder político é um processo semelhante a fatiar um pedaço de queijo, o que permitiria, por acúmulo de força ideológica e de posições no aparato, chegar a um ponto onde o queijo (leia-se, o poder político) passa às mãos dos dominados de maneira gradual e quase imperceptível para os dominantes, algo assim como uma "revolução sem revolução", nos dizeres de Zizek ${ }^{16}$. A ideia caminha

14 Esta permissividade desaparece quanto mais autoritária seja a forma de governo imperante. 15 O Estado pode assumir formas de organização sindical ou de partidos de "esquerda", mas os primeiros somente são reconhecidos como organizações de vendedores de força de trabalho, e os segundos na medida em que se comprometam a respeitar o Estado de direito, não atentando contra ele. $16 \operatorname{Ver}($ ZIZEK, 2004). 
no sentido contrário ao apontado sobre a centralidade do poder político no Estado capitalista e sua não fragmentação.

Em uma derivação dos pressupostos que fazem da sociedade civil uma entidade estatal, aparece, por sua vez, o privilégio da "guerra de posições", entendida principalmente como avanços na tomada ou ocupação de posições na sociedade civil (assumida como Estado) e no aparato de Estado (também entendido como Estado), conduzindo no longo prazo à conquista do Estado e, consequentemente, do poder.

O Estado capitalista é uma entidade que pode assumir posições das classes dominadas. Porém, enquanto classes dominadas ${ }^{17}$. Portanto, não se trata de um território, espaço ou relação que possa ser surpreendido por forças constituintes de outro poder de classes. Em definitiva, uma coisa é a permissividade da sociedade civil para incorporar posições contrárias ao poder. Mas essa permissividade já não ocorre quando se tratam de posições no Estado. Isto é mais factível no aparato de Estado. Porém, como veremos a seguir, aquela é uma tendência que leva as classes dominantes a deixar a administração do aparato nas mãos de outras classes, como fórmula para encobrir seu domínio.

Na mesma linha de sobredimensionar a sociedade civil, está a noção do Estado como "hegemonia revestida de coerção", onde finalmente se assume que a sociedade civil é o elemento determinante do poder político, o qual é protegido (revestido) pela coerção, atividade que se supõe própria do Estado. Seria preciso inverter a fórmula anterior e apontar que o Estado é, primordialmente, coerção/consenso revestido de consenso, com o qual nos aproximaríamos da noção de "sistema de dominação" e, o mais importante, onde o Estado manifesta sua preeminência em matéria de poder político e domínio, como sugere a formulação apontada anteriormente.

Em todos os processos revolucionários conhecidos, gestaram-se processos de poder dual e, a partir do campo popular, esse novo poder, gérmen de um novo Estado que emerge junto com às relações de poder que serão destruídas, concretizado-se historicamente

$17 \operatorname{Ver}($ ZIZEK, 2004). 
nos sovietes, nos exércitos rebeldes, conselhos operários, ou seja, em entidades que portam e sintetizam força social constituinte de novas relações sociais. É claro que podem surgir novas formas de uma sociedade civil, tal como novas formas de ensino e de comunicação, mas não possuem a mesma importância em matéria de poder político que as entidades anteriores.

Por tudo o que foi apontado anteriormente, é necessário enfatizar que entre a sociedade civil e o Estado não existe uma linha de continuidade em matéria de poder político. Estamos falando de poderes qualitativamente diferenciados. O Estado, como relações de poder político condensadas, é aquele que tem a capacidade de organizar a vida em comum de maneiras específicas, em função de interesses particulares de classes, tarefa que as instituições da sociedade civil não podem levar a cabo, por estarem orientadas predominantemente a tarefas de educação nos valores dominantes e, a partir daí, de obtenção do consentimento dos dominados.

Em termos metafóricos, poderíamos afirmar que não é galgando posições na sociedade civil que se chega às escadas que dão acesso ao Estado, porque entre uma escada e outra há uma ruptura chamada revolução, que implica ruptura de relações sociais de poder e domínio ${ }^{18}$. Existe, portanto, mais ruptura que continuidade em matéria de poder político entre o Estado e a sociedade civil.

A debilidade das relações que criam sentido de comunidade a partir do Estado pode ser compensada com a ação das instâncias da sociedade civil. Porém, as relações de poder político não podem ser derivadas para a sociedade civil. E, se algumas de suas instituições (escolas, igrejas, meios de comunicação) as assumissem, terminariam transformando-se em Estado.

\section{HIATO ENTRE ESTADO E APARATO DE ESTADO: CHAVES PARA PENSAR OS GOVERNOS POPULARES}

O aparato de Estado é primordialmente a coisificação das relações sociais que constituem o Estado. O aparato de Estado está formado por instituições como o Banco Central, o Parlamento, o Poder

18 Já apontamos o erro que é supor que - mantendo a metáfora - subindo pelo Estado capitalista, este irá mudando de conteúdo de classe quanto mais alto cheguemos. Em todos os casos o que se oculta é o tema da revolução. 
Executivo com seus Ministérios de Estado, o Superior Tribunal Federal e demais Tribunais, Ministérios Públicos, as Forças Armadas, a polícia, o sistema penitenciário, as prisões, as empresas estatais, etc. - todas elas hierarquizadas.

Também fazem parte do aparelho de Estado os servidores que trabalham nessas instituições. Esses funcionários também estão sob determinada hierarquia, e chamamos de classe reinante o setor que ocupa as posições mais altas e de maior hierarquia dentro do aparelho, como Presidente, ministros de Estado, diretores e demais altos funcionários de ministérios ou do Banco Central, os altos comandos militares, juízes do Supremo Tribunal Federal, as autoridades da Câmara de deputados e do Senado.

Por último, conformam também o aparato de Estado o corpo constitucional, as leis e normas estabelecidas.

Se o Estado é o centro do poder político, onde os interesses das classes dominantes são os que prevalecem na organização da vida em comum, o aparato de Estado é a instância que administra esse poder uma vez que seu funcionamento em geral está determinado pelos interesses que prevalecem no Estado. Neste sentido, a distinção entre classes dominantes e classe reinante é fundamental.

Se nos referimos à sociedade mexicana, podemos dizer que os Slim, Azcárraga, Larrea, Salinas Pliego, Aramburu etc. (ou para a sociedade brasileira os Odebrecht, os donos de O Globo ou da Folha de S. Paulo) formam parte das classes dominantes, isto é, daquelas classes que detêm o poder político e que têm um peso específico na organização da vida em comum de acordo com seus interesses, enquanto os Salinas de Gortari, Fox, Calderón e Peña Nieto no México (ou Cardoso, Lula da Silva, Rousseff e Temer no Brasil) foram a cabeça da classe reinante nas últimas décadas. Um erro comum e nada menor é apontar os presidentes da república e demais altos funcionários do aparelho de Estado como aqueles que detêm o poder. Não é difícil perceber o erro dessa confusão provocada pela fetichização do Estado pelo capital, fazendo com que se perceba a vida social de forma distorcida e opaca.

Para as classes dominantes no capitalismo, deixar a administração do aparato de Estado nas mãos de outras classes lhes permite 
alimentar a ficção de um Estado socialmente neutro, ocultando seu caráter de classe. Por isso são excepcionais as situações em que presidentes ou primeiros-ministros são diretamente membros das classes dominantes. Em períodos recentes empresários como Mauricio Macri ou Donald Trump chegaram respectivamente à presidência da Argentina e dos Estados Unidos, mas esses casos configuram exceções que apenas confirmam a regra antes apontada.

Se o Estado é o centro do poder político, esse poder não está em jogo em qualquer consulta eleitoral, nem sequer naquelas que definem o cargo principal dentro do aparelho de Estado, seja tal cargo o de presidente ou de primeiro-ministro. O que se define nas consultas eleitorais são as pessoas que ocuparão posições relevantes no aparelho de Estado. Em outras palavras, não é o poder político que está em disputa mesmo nas consultas eleitorais mais importantes. Somente estão em disputa os funcionários e as forças políticas que administrarão esse poder político.

Se as mudanças de cargos se realizam entre partidos e figuras partidárias que representam interesses das classes dominantes, isso provocará reacomodações no interior do bloco no poder ${ }^{19}$. E se são forças e figuras que em diversos graus buscam mudar a ordem imperante, isso poderá expressar mudanças potenciais nas correlações de força entre as classes fundamentais, mudanças que deverão ser validadas na gestão desses governos. A possibilidade de que as mudanças nas correlações de força entre as classes fundamentais assumam uma orientação de ruptura ou apenas reformista, por exemplo, estará marcada pelos projetos em marcha e pelo modo como a própria gestão do novo governo se orienta para uma ou outra meta.

Nesses dois últimos parágrafos se condensam o espaço teórico para explicar a conformação de governos populares - de particular relevância na região a partir do início do novo século - e, ao mesmo tempo, os limites que tais governos enfrentam, na medida

19 Ou seja, alterações na articulação/confronto das diferentes classes, frações e setores das classes dominantes, segundo os graus de força social de que dispõem em determinados momentos históricos, nos quais algumas frações e/ou setores se tornarão hegemônicos no bloco, o que indica que será em torno de seus projetos que passarão a se articular e confrontar o restante das frações e setores dominantes. Sobre esse ponto, ver Osório (2014). 
em que se posicionam num aparelho que responde a interesses estatais específicos. O aparelho de Estado não é uma garrafa vazia e transparente, que ganhará a cor do líquido que a preencha conforme formulado por diversas correntes reformistas -, mas sim um território carregado de interesses de classe, com labirintos e armadilhas prontas para obstruir os projetos de forças sociais e políticas que rejeitem ou questionem a ordem existente.

OS GOVERNOS POPULARES: UM ENCLAVE NO APARATO DE ESTADO BURGUÊS

Não é um tema irrelevante que figuras de partidos políticos e/ ou movimentos sociais que se propõem a modificar ou mesmo a superar a organização capitalista ganhem eleições e cheguem a ocupar posições relevantes dentro do aparato de Estado. Isso gera problemas não apenas ao aparelho, mas também ao próprio Estado, pois parte importante das funções exigidas às relações de poder político e domínio é realizada através do aparato de Estado.

Uma interpretação recorrente em situações como a anteriormente assinalada afirma que não apenas teriam vencido as eleições e os cargos em disputa - seja para presidente, deputados, senadores, etc. -, mas se acredita haver conquistado o poder político ou parte dele. A partir dessas considerações se explica o sentido de propostas como iniciar a construção do socialismo ${ }^{20}$. Mas entre o capitalismo e o início da construção do socialismo há um problema nada irrelevante chamado revolução e o estabelecimento de um novo poder político.

Em uma versão que relativiza um pouco a anterior, argumentase que nas eleições não se ganhou o poder político, mas sim posições importantes para avançar neste sentido. Mas avançar pode ser entendido como seguir realizando mudanças, muitas delas importantes, para o qual é necessário seguir ganhando eleições para manter ou aumentar os cargos e as posições alcançadas, o que em algum momento terá como consequência

20 Isso foi o que se propôs na Venezuela no período em que governava o comandante Hugo Chávez: construir o "socialismo do século XXI" tornou-se uma meta do processo. Álvaro García Linera, vicepresidente da Bolívia, colocou a questão da seguinte forma: "[...] está claro que esta construção do Estado que estamos fazendo hoje [...] não é a modernização clássica [...] mas sua transição é evidentemente para o socialismo". Na Conferência magistral de Álvaro García Linera (2010). 
que a correlação de forças se modifique a favor dos dominados e em detrimento dos dominantes, resolvendo-se assim a questão sobre quem detém o poder ${ }^{21}$.

Descrevendo os pontos centrais que possibilitaram que 0 "ponto de bifurcação" se resolvesse em favor das "forças revolucionárias", García Linera aponta a vitória eleitoral no referendo revogatório (aprovado por meio de Lei do Senado) do mandato de Evo Morales, em agosto de 2008, na Bolívia; a derrota da escalada golpista, entre agosto e setembro de 2008, e, finalmente, a aprovação da nova Constituição, através de referendo, em janeiro de 2009. O fio condutor dessa leitura é que com tais episódios teria se consolidado "um novo bloco de poder", encerrando "o ciclo da crise estatal na Bolívia"22.

García Linera destaca a necessidade de entender a revolução como processo, o que, acredito, ninguém questionará; mas nesse processo revolucionário necessariamente deve ocorrer a quebra do antigo Estado, a derrota das classes dominantes, a derrota ou desintegração dos antigos aparelhos armados e a conformação de um novo exército, como povo em armas, assuntos que não são abordados ou aparecem com sérias confusões nas intervenções de García Linera.

Assim, por exemplo, o "ponto de bifurcação", entendido como "[...] momento de confronto aberto ou da medição de forças [...]", em que "[...] ou se reconstitui o velho bloco de poder conservador ou se termina com o empate catastrófico e se consolida um novo bloco de poder [...]", é localizado no processo boliviano na derrota da direita golpista em setembro de 2008 e assumido como "[...] vitória militar do povo [...]”; García Linera afirma que o triunfo das forças revolucionárias foi alcançado por um processo de "[...] mobilização social geral, de todas as forças que tinha o Partido [MAS], o camponês, o movimento indígena, o

21 García Linera é um dos principais porta-vozes dessa formulação recentemente. Ver seu artigo "El Estado y la vía democrática al socialismo", em Nueva Sociedad, n²59, Buenos Aires, septiembreoctubre de 2015. Já em 2010 García Linera havia assinalado que "o que estamos fazendo [...] como horizonte de nossa ação política, é encontrar uma via democrática para a construção de um socialismo de raízes indígenas, que chamamos de socialismo comunitário". Ver a antes citada Conferência magistral titulada "La construcción del Estado", op. cit. (itálicas J.O.).

22 Ver a referida Conferência magistral de Álvaro García Linera (2010), intitulada "La construcción del Estado". 
movimento cooperativista, as comunidades, os ponchos rojos, os ponchos verdes*, produtores de folhas de coca, do Chapare, dos Yungas [...]", e também pelo "[...] respeito institucional das Forças Armadas" (GARCÍA LINERA, 2010, não paginado)23.

E como se produziu a mudança das Forças Armadas bolivianas, expressão da violência concentrada do Estado capitalista, numa instituição que agora opera com outro sentido de classe? A resposta de Garcia Linera é de uma enorme ingenuidade teórica e política: a partir de uma "[...] articulação institucional cultivada pelo presidente Evo na redefinição de uma nova função das Forças Armadas na democracia". Nisso residiria "[...] o respeito institucional das Forças Armadas [...]" (bolivianas) e, como bem agrega, não ao processo revolucionário, mas sim “[...] em defesa da democracia”. 24

A mesma ideia é formulada novamente em outra ocasião, mas sem referência às Forças Armadas em particular. Neste sentido García Linera defende que "[...] durante uma insurgência social por fora do Estado, e por dentro das próprias estruturas institucionais do Estado, é preciso derrotar o velho poder decadente, atravessando [...] o ponto de bifurcação" (GARCíA LINERA, 2015, p. 158).

Ninguém pode desvalorizar a relevância dos momentos acima apontados, bem como a força social alcançada, os quais permitiram iniciar a "descolonização do Estado" e reconhecer na Constituição os direitos dos povos indígenas; a nacionalização dos hidrocarbonetos; a conformação de uma Assembleia Constituinte; a nacionalização das empresas de telecomunicações e de outras empresas. Todos esses elementos, somados aos triunfos eleitorais

* N.T.: Os ponchos rojos e os ponchos verdes são milícias que defendem seu território e buscam a autonomia e dignidade indígena, originárias respectivamente de Ayachachi (Provincia de Omasuyos, Departamento de La Paz) e Aramasí (Província de Tapacrí, Departamento de Cochabamba).

23 Trecho entre aspas da Conferência magistral de Álvaro García Linera (2010).

24 Conferência magistral de Álvaro García Linera, "La construcción del Estado", op. cit. (itálico JO). Sob o governo de Salvador Allende, o Comandante em Chefe das Forças Armadas do Chile, general Carlos Prats, desarmou os militares golpistas no "tanquetazo" (processo que se analisa mais adiante), fazendo-os descer dos tanques em que estavam posicionados à frente da casa de governo, em julho de 1973. Dois meses depois, em setembro de 1973, as "institucionais" Forças Armadas chilenas realizaram o golpe militar que estabeleceu a ditadura do general Augusto Pinochet, que tinha substituído Prats no comando do Exército. Muitas pessoas naquele então, da mesma forma como parece fazer García Linera atualmente, acreditaram que o braço armado do Estado poderia manter-se disciplinado frente à institucionalidade vigente. Existe um ponto (de bifurcação?), quando não há mais saídas, no qual o acirramento dos enfrentamentos sociais obriga a intervenção militar, salvo quando o processo não seja tão radical e não implique maiores agudizações. 
e aos triunfos anti-golpistas, estão muito distantes, entretanto, de resolver o problema do poder na Bolívia, de produzir um "ponto de bifurcação" (ou triunfo da revolução JO) ou que tenha redundado em uma inclinação na direção das forças revolucionárias ${ }^{25}$. Nesse sentido, o vice-presidente era mais claro nos anos anteriores, quando afirmava que se buscava construir um "capitalismo andino-amazônico" na Bolívia, cuja base era um "[...] processo de redistribuição pactuada do poder” (GARCÍA LINERA, 2007, p. 165).

Os chamados governos populares da Venezuela e da Bolívia se enredaram na confusão entre Estado e aparato de Estado, e perderam um tempo precioso do ponto de vista da força social com a qual contavam no momento em que ascenderam ao aparato de Estado. Nesta oportunidade, as forças sociais revolucionárias poderiam ter sido incrementadas no sentido de resolver quais interesses sociais e quais interesses políticos organizam a vida em comum, e, finalmente, qual poder político se impõe.

No caso da Venezuela, em meados de 2017, produziram-se mudanças de grande importância. Em meio a uma longa agudização da ofensiva opositora no plano local e internacional durante a primeira metade de 2017, a convocação de eleições e a posterior conformação da Assembleia Nacional Constituinte se converteram em uma comoção política que reanimou as forças populares e o próprio governo, que estavam já por um longo período na defensiva e em desarticulação. Isso lhes permitiu retomar novamente a iniciativa política ${ }^{26}$. A ingerência e as ameaças do governo dos Estados Unidos aumentaram, fortalecendo a reorganização antiimperialista e nacionalista. Este novo impulso levou à radicalização do processo e à desarticulação dos principais centros e cabeças da ofensiva opositora interna.

O particular caráter nacionalista das Forças Armadas venezuelanas e o fato de o comandante Hugo Chávez ter sido um de seus membros são alguns elementos que explicam o respeito institucional que as

25 Em um artigo jornalístico intitulado "La Revolución Rusa, según García Linera”, Emir Sader (2017) também sustenta que o "ponto de bifurcação" na Bolívia foi a derrota do "[...] golpe de Estado cívico-prefeitural de setembro de 2008" (SADER, 2017).

26 Esse artigo foi concluído no dia 16 de outubro de 2017, data na qual se anunciou que o Partido Socialista Unificado da Venezuela (PSUV) ganhou 17 dos 23 governos que estavam em disputa nas eleições de 15 de outubro desde mesmo ano. 
Forças Armadas manifestam até hoje em relação ao governo de Nicolás Maduro. Nesse marco foi realizada a convocatória, teve andamento a Assembleia Nacional Constituinte, a destituição da Procuradoria Geral e foram reduzidas as atribuições da Assembleia Nacional onde estavam entrincheiradas institucionalmente as forças opositoras.

É relevante que forças críticas ao capital vençam processos eleitorais sempre que possível. Porém, é preciso ter em vista que, em uma estratégia de poder, são muito altas as probabilidades de que até mesmo as conquistas efetuadas deverão ser ultrapassdas pela força social em sua passagem para se converter em força social constituinte. Esta força social pode se ver fortalecida e potencializada a partir das posições alcançadas dentro do aparelho de Estado, mas precisam ultrapassá-lo no intuito por superar o capitalismo e suas relações. A contenção dos movimentos sociais na Venezuela e na Bolívia, que ajustam suas mobilizações e seu auge às conjunturas eleitorais ou nos momentos em que a ofensiva reacionária os alcança, não deixa de ser um problema na perspectiva da radicalização dos processos.

\section{BREVE INTERMEZZO SOBRE GOVERNOS POPULARES E A NECESSIDADE DE RUPTURAS INSTITUCIONAIS}

Os principais teóricos e políticos que deram vida à "via chilena ao socialismo" - cuja maior conquista foi o triunfo e ascensão de Salvador Allende (1970-1973) ao governo-, sustentaram a ideia de que era possível ir modificando o aparelho de Estado e o Estado por um caminho que respeitasse a institucionalidade vigente. Esse processo se efetivaria realizando mudanças apoiadas na força outorgada por consecutivos triunfos eleitorais - ou em mais uma tentativa de realizar a revolução sem revolução. Não se pode dizer que não se avançou, e muito, na organização, distribuição de terras, empresas ocupadas, expropriação do capital estrangeiro das minas de cobre, etc. Entretanto, o golpe militar de 1973 evidenciou que se, por um lado, as forças populares queriam avançar em direção a um novo poder através de caminhos institucionais, de outra parte, as classes dominantes e as Forças Armadas estavam dispostas a "sacrificar" seu respeito às normas institucionais com o objetivo de impedir esse avanço e preservar seu poder. 
O presidente Salvador Allende não deixou de ter razão quando em suas últimas mensagens pelo rádio, já avançado o golpe militar e um pouco antes de sua morte, fez um chamado aos trabalhadores, aos setores populares e aos estudantes a não se deixarem massacrar, por milhares de homens fardados posicionados nas ruas e locais de trabalho. Porém, houve conjunturas no processo chileno nas quais o avanço que implicou contar com um governo popular, que tinha por meta chegar ao socialismo, alcançou pontos culminantes em matéria de força social disponível, de desorganização dos setores dominantes e de confusão no seio das Forças Armadas e militares. Nestas conjunturas residia o ponto de inflexão a partir do qual a ruptura institucional imperante era não apenas necessária, senão possível. Um dilema com o qual se enfrenta qualquer processo de transformação com perspectivas socialistas que alcance posições substanciais no aparelho de Estado.

Um desses momentos se produziu em julho de 1973, quando, no dia 29 daquele mês, um setor militar de um regimento de blindados tentou levar a cabo um motim, com tanques nas ruas, chegando inclusive à sede do governo, o Palacio de La Moneda, com o objetivo de fomentar um golpe militar -, no episódio batizado de "tanquetazo". A ação não conseguiu atrair maiores forças militares ou civis, nem o apoio dos altos comandos dos três ramos das Forças Armadas. Assim, os militares golpistas foram submetidos por outros setores e corpos militares.

Como resposta a este motim, o governo, as centrais sindicais e os partidos políticos que conformavam a Unidade Popular convocam uma grande concentração no centro de Santiago para expressar seu rechaço à ação golpista. Massivas marchas de operários, funcionários públicos e do setor privado, camponeses, estudantes, trabalhadores da limpeza com seus caminhões, donas de casa, moradores das comunidades periféricas, radicalizados, lotaram as ruas de Santiago e do restante das principais cidades do país.

Diante da enorme força social disponível, esse era o momento de evidenciar a cumplicidade dos partidos da direita chilena e da Democracia Cristã com o fracassado motim militar e de reivindicar a destituição de seus parlamentares. Era o momento também de denunciar as organizações empresariais mancomunadas ou 
solidárias com a ação militar e de decretar a passagem de suas empresas e bancos ao setor social da economia; de questionar os comandos militares diretos dos golpistas, pela incapacidade de manter o respeito institucional de suas tropas, destituindo-os; de convocar a população a ocupar ruas e postos de trabalho até excluir as instituições daqueles potenciais golpistas, ou decretar seu fechamento; de convocar a população à conformação da Assembleia do Povo proposta desde julho de 1972 pelo Movimento de Esquerda Revolucionária (MIR-Movimiento de Izquierda Revolucionaria), uma Constituinte para definir a reorganização da vida em comum sobre novas bases.

Tratava-se de uma conjuntura particular nas quais as Forças Armadas se encontravam questionadas, e, inclusive, desorganizadas por uma operação que tomou forma a partir de seu interior e que surpreendeu o alto comando. O general Carlos Prats, um militar institucional e leal ao governo de Allende, não havia renunciado ainda ao cargo de Comandante em Chefe das Forças Armadas, fazendo-o apenas em agosto daquele ano, razão pela qual o general Augusto Pinochet, que se converterá em um dos líderes do golpe de setembro, ainda não contava com a força e a coordenação do setor militar golpista. Este foi um momento para grandes decisões porque os setores populares se agitaram com a tentativa golpista e manifestaram disposição de assumir maiores responsabilidades pelo avanço e defesa do processo.

Além disso, nas eleições legislativas de março de 1973, três meses antes da tentativa golpista, as organizações políticas que davam vida a Unidade Popular tinham conquistado $43 \%$ dos votos em escala nacional, o que denotava o elevado apoio com que contava o governo. Esse apoio popular deteve a tentativa de "golpe institucional" que seria sustentado pelo Congresso, pelo Judiciário e por contingentes civis protofascistas que já operavam como forças paramilitares.

Nada do mencionado se concretizou. Pelo contrário, após o tanquetazo, começou a vigorar a Lei de Controle de Armas, aprovada em outubro de 1972 pelo Congresso, com revistas militares nas comunidades de periferia, fábricas e organizações populares em busca de armas. Com isso, não apenas não foram 
enfrentados os poderes e instituições que já revelavam seus limites para sustentar um processo de transformação institucional, mas inclusive foram reforçados seus poderes, resultado na desmoralização dos setores populares.

A resposta popular também teria outra envergadura se tivessem sido impulsionadas a partir do governo e de fora deste as iniciativas organizativas e de ação que os setores populares foram gerando no decorrer do processo, tais como os comandos comunais, a articulação de sindicatos e trabalhadores em cordões industriais, formas de organização de camponeses e indígenas para recuperar terras expropriadas, organização de moradores e setores pobres urbanos e populares em geral para enfrentar o desabastecimento e o mercado paralelo de especulação com bens e produtos, e incipientes formas de defesa armada em diversos setores e organizações populares.

Impulsionar e favorecer todas essas iniciativas organizativas e de ação exigia que os partidos e as autoridades de governo não gastassem todas suas cartas em uma só forma de resolver o conflito de classes: as formas institucionais. A luta de classes não é um duelo entre cavalheiros, em que previamente se escolhe a arma com a qual ocorrerá o enfrentamento. É preciso prever os possíveis cenários e um deles é aquele em que se deve atuar com outra lei, já não com a lei estabelecida. Do contrário fica-se de mãos atadas à forma prévia, apostando todas as fichas numa só opção.

O final desta história é conhecida. O presidente se suicida no palácio do governo, enquanto aviões militares bombardeiam o Palacio de La Moneda e os cordões industriais. Pinochet e os demais comandantes em chefe das Forças Armadas conformam a Junta Militar, que governará o país por 16 anos, até 1989. Assim se deu por encerrado ao projeto de revolução institucional, com milhares de mortos e desaparecidos.

As novas propostas de "vias democráticas ao socialismo", como aquela apresentada por García Linera, na Bolívia, poderiam fazer um balanço mínimo da experiência do governo de Salvador Allende, e das dificuldades políticas que essa experiência evidenciou. Ao fim e ao cabo, aquele processo atuou a partir de uma estratégia similar a de uma via institucional e democrática ao socialismo. 


\section{PROBLEMAS NÃO CONTEMPLADOS NAS PROPOSTAS DE "VIA DEMOCRÁTICA AO SOCIALISMO"}

O capitalismo apresenta uma série de particularidades que limitam - quando não liquidam - a proposta de "vias democráticas ao socialismo", pelo menos nas condições atuais da correlação de forças em escala mundial. A primeira remete às relações sociais de produção, as quais, no capitalismo, possuem um papel central na reprodução dessa organização social, dado que, por mais que as relações se agudizem, delas obtém-se como resultado sempre capital e trabalho. Não é o caso, por exemplo, nas relações do senhor com os servos no feudalismo. Se a exploração se agudizasse, com a cobrança de maiores tributos pelo senhor, isso podia fazer com que os servos abandonassem as terras e buscassem refúgio e formas de subsistência nas incipientes cidades. Ou seja, a agudização da exploração permitia, naquele caso, romper as relações sociais. Isso não ocorre de nenhuma forma substantiva no capitalismo. No feudalismo não eram as relações sociais de produção o elemento fundamental da reprodução daquela ordem social, mas sim os elementos ideológicos, religiosos e culturais que operavam de modo prioritário naquela reprodução.

Justamente por isso foi possível que, no seio do feudalismo, as relações sociais feudais pudessem se desintegrar, permitindo a geração e posterior expansão de relações sociais cada vez mais plenamente capitalistas, nas quais se produz capital. Isso permitirá a burguesia, em dado momento, requerer sua incorporação ao regime de domínio imperante e, mais tarde, reivindicar e lutar pela hegemonia do Estado.

É na força que a burguesia ganha como parte desse processo, aliada ao fato de que, tal como as antigas classes dominantes, também é uma classe exploradora, onde repousa a possibilidade de que possam se estabelecer acordos e alianças entre a nova classe que se tornará dominante - a burguesia - e as antigas - os senhores, a nobreza, o alto clero. Daí o fato de a transição do feudalismo ao capitalismo não assumir necessariamente formas próprias de uma guerra entre classes. Nesta perspectiva, não é a revolução francesa o modelo de revoluções burguesas, mas, ao contrário, a revolução inglesa. 
No capitalismo, não existe a possibilidade de que emerjam do seu interior relações socialistas, o que limita, a partir deste terreno, o empoderamento prévio à revolução por parte da classe revolucionária.

Portanto, na medida em que o proletariado traz consigo um projeto societário em que desaparecerão a exploração e o domínio de classes, as possibilidades de alianças e acordos com as velhas classes dominantes são praticamente nulas. O proletariado é a negação do projeto burguês. Isso faz com que as possibilidades de transições democráticas ao socialismo sejam reduzidas, ou mesmo nulas. É possível que cheguemos a um ponto da correlação de forças mundial em que os avanços da revolução coloquem a burguesia em uma posição na qual se encontre encurralada em espaços determinados e abandone o enfrentamento, na lógica de defesa de seu poder e de seus privilégios a qualquer custo.

Conforme já indicamos antes, nada disso deve ser interpretado como uma negação da luta no campo institucional no capitalismo. Não existem espaços e formas de luta negadas na busca por acumular forças. Mas tratamos de estabelecer as determinações e os limites enfrentados por essas lutas no atual estado de coisas.

\section{DETERMINAÇÕES DO ESTADO DEPENDENTE}

Do assinalado nos pontos anteriores sobre o Estado capitalista em geral cabe registrar algumas particularidades do Estado dependente.

3.1. No seio do sistema interestatal mundial, o Estado dependente é um Estado subsoberano. De cara, isto significa um poder estatal subordinado a outros poderes estatais. Também implica a presença de um poder que opera descentrado em respeito à sociedade no qual se constitui, nutrido por modalidades de reprodução que culminam em mercados exteriores. Esta condição não significa que o Estado não conte com o poder político para definir e organizar a vida em comum no interior da organização social em que atua e opera. Isso implica em romper com a equação da ciência política tradicional que supõe ser o Estado um equivalente a soberania. Essa formulação desconhece a heterogeneidade econômica e estatal que o capitalismo conforma no nível do sistema mundial. 
Por sua vez, implica romper com a ideia de que as carências em matéria de soberania supõem incapacidades para o exercício do poder político por parte das classes dominantes locais.

3.2. No plano econômico do sistema mundial operam mecanismos de transferência de valor (de lucros por investimento, de juros da dívida etc.) de umas a outras economias que dão forma a capitalismos desenvolvidos e capitalismos dependentes. Quando ditas transferências se produzem por maiores ou menores composições orgânicas, e, portanto, de produtividade, tecnologia e conhecimentos, falamos de intercâmbio desigual. As modalidades de inserção no mercado mundial e de reprodução do capital encorajam que o capital no mundo dependente tenha condições de apropriarse de parte do fundo de consumo e de vida dos trabalhadores para transferi-lo ao fundo de acumulação do capital. A esta modalidade particular de exploração se denomina superexploração, a qual se vê possibilitada pela presença de enormes contingentes de população excedente em relação às necessidades do capital, gerados pela própria dinâmica da acumulação.

3.3. O predomínio da superexploração sob diversas formas agudiza os conflitos sociais e debilita as relações que geram sentido de comunidade. Esta é uma das principais razões pelas quais, na história política dos Estados latino-americanos, se verifique a tendência ao predomínio de diversas formas autoritárias, bem como a dificuldade destes Estados em assentar-se de maneira mais duradoura em formas democráticas ${ }^{27}$. Não é falta de desenvolvimento político a explicação para isso, mas é expressão das formas particulares de reprodução do capitalismo dependente.

3.4. Em uma economia sustentada na espoliação das condições básicas de vida do grosso da população e submetida pelas classes dominantes hegemônicas a processos de despojo de valor para as economias desenvolvidas, deriva-se uma agudização dos conflitos sociais e da luta de classes, com maior força pelo desenvolvimento pleno das classes sociais do capitalismo e de seus enfrentamentos. Nestas condições, o Estado dependente tende a se converter em um elo frágil da corrente de dominação

27 Isso implica questionar ideias que tentam explicar o autoritarismo presente na região como resultado de deficiências de cultura política. 
mundial do capital, a qual coloca em evidência de maneira permanente a atualidade da revolução ${ }^{28}$.

3.5. A agudização dos conflitos sociais no capitalismo dependente e da superexploração trazem consequências sobre o Estado de direito e o peso da lei os quais são minados e aplicados discricionariamente. As leis não escritas têm um peso significativo na vida social. As instituições do Estado, por sua vez, manifestam fragilidade, não por imaturidade, senão pela particularidade que apresenta a imbricação do econômico com o político. Tudo o que foi dito é necessário para sustentar a condição de subsoberania no sistema interestatal, as particulares formas de exploração no plano local e as transferências de valor.

3.6. Frente a instabilidade das instituições, tendencialmente frágeis, alimentada também pela débil legitimidade das autoridades, emerge a tendência a outorgar à classe reinante maiores espaços de ação e decisão no âmbito do aparato de Estado. Neste quadro é que operam as condições para regular a emergência de mandos autoritários e de governos encabeçados por caciques ou caudilhos políticos nos Estados dependentes. ${ }^{29} \mathrm{~A}$ inexistência de estruturas produtivas complexas e a precoce monopolização da economia em seus diversos setores propicia o rápido surgimento do grande capital que passa a predominar na economia e no Estado dependente. Isso provoca que prevaleça no interior do bloco no poder uma subordinação do restante dos capitais aos setores e frações hegemônicas, em vez de esses conflitos pela repartição dos lucros e em torno a projetos econômicos se fazerem sentir com força no Estado e na sociedade ${ }^{30}$.

3.7. Este processo foi reforçado pela massiva entrada de capital estrangeiro na indústria local desde os anos cinquenta do século XX, que se viu reforçado no século XXI com as alianças do

28 Este tema desenvolvi no livro Explotación redoblada y actualidad de la revolución. Refundación societal, rearticulación popular y nuevo autoritarismo (OSÓRIO, 2009).

29 O tema apresenta matizes que aqui, pelo nível geral da análise, não podemos desenvolver. Apenas a título de exemplo, cabe registrar que não é o mesmo o caudilhismo de Stroessner, no Paraguai, que o de Chávez, na Venezuela, por orientação política, pelas forças sociais que os apoiam, pelas políticas sociais colocadas em prática, pela relevância na região, etc.

$30 \mathrm{Na}$ Argentina e no Brasil é possível perceber na história recente conflitos relevantes entre frações e setores do capital local pela repartição do lucro ou por projetos econômicos conflitantes, entre setores industriais e setores ligados a produção primária para exportação. 
grande capital local com o capital externo após a emergência de segmentos e elos produtivos de cadeias globais, com a expansão do capital financeiro pelo conjunto do sistema e com importantes investimentos externos no setor primário.

3.8. Diante do peso de padrões de reprodução do capital orientados ao mercado exterior na história econômica latino-americana, prevalece no capitalismo dependente uma espécie de esquizofrenia social nas classes dominantes da região. Frente a necessidade de estar abertas aos mercados exteriores e de limitar medidas protecionistas, operam defendendo posições liberais no âmbito econômico, sustentando, no entanto, posições conservadoras no terreno político e social. Isto, que já havia sido expresso na segunda metade do século XIX, segue apresentando-se com força desde o último terço do século $X X$ até nossos dias, com governos de direita no campo político e liberais na esfera econômica - como ocorre desde as ditaduras civil-militares. O surgimento de governos populares progressistas no século XXI moderou esta tendência que volta a ganhar vida depois da derrota eleitoral destes governos (com Maurício Macri, na Argentina) ou a instauração de golpes civis (e a entronização de Michel Temer no Brasil).

\section{REFERÊNCIAS}

ALTHUSSER, Louis. Ideología y aparatos ideológicos de Estado. México (D.F.): Comité de Publicaciones de los Alumnos de la Escuela Nacional de Antropología e Historia, 1974.

ÁVALOS TENORIO, Gerardo; HIRSCH, J. La política del capital. México (D.F.): UAM Xochimilco, 2007.

ÁVALOS TENORIO, Gerardo. México; nudo poder y disolución del Estado. Veredas, México (DF), n. 20, p. 97-119, 2010.

ÁVALOS TENORIO, Gerardo. La estatalidad en transformación. México (DF): Itaca; UAM, 2015.

GARCÍA LINERA, Álvaro. Las reformas pactadas. Entrevista por José Natanson., Nueva Sociedad, Buenos Aires, p. 160-172, n. 209, mayo./jun. 2007.

GARCÍA LINERA, Álvaro. La construcción del Estado. México (DF): Facultad de Derecho UBA, 9 abr. 2010. Disponível em: <http:// 
cidac.filo.uba.ar/conferencia-magistral-de-C3\%A1lvarogarc\%C3\%ADlinera-\%E2\%80\%9Cla-construcci\%C3\%B3n-del-estado\%E2\%80\%9Dfacultad-de-derecho-uba-9>. Acesso em: 31 mayo 2016. GARCÍA LINERA, Álvaro. El Estado y la vía democrática al socialismo. Nueva Sociedad, Buenos Aires, n. 259, sep./oct. 2015. GRAMSCI, Antonio. Notas sobre Maquiavelo, sobre política y sobre el Estado moderno. México (D.F.): Juan Pablos, 1975. HOLLOWAY, John. Cambiar el mundo sin tomar el poder: el significado de la revolución hoy. Buenos Aires: Ediciones Herramienta; Universidad Autónoma de Puebla, 2002. MARX, Carlos. El capital, t. III. Séptima reimpresión. México (DF): Fondo de Cultura Económica, 1973.

OLIVER, Lucio. El Estado ampliado en Brasil y México. México (DF): Unam, 2009.

OSORIO, Jaime. O Estado no centro da mundialização: a sociedade civil e o tema do poder. São Paulo: Outras Expressões, 2014.

OSORIO, Jaime. Explotación redoblada y actualidad de la revolución: refundación societal, rearticulación popular y nuevo autoritarismo. México (DF): UAM; Itaca, 2009.

POULANTZAS, Nicos. Estado, poder y socialismo. México (DF): Siglo XXI, 1979.

ROUX, Rhina. El Príncipe fragmentado: liberalización, desregulación y fragmentación Estatal. Veredas, n. 20, México, Departamento de Relaciones Sociales, UAM-Xochimilco, primer semestre de 2010.

SADER, Emir. La Revolución Rusa, según García Linera. Página 12, Buenos Aires, 22 jun. 2017. Disponível em: <https://www.pagina12. com.ar/45597-larevolucion-rusa-segun-garcia-linera>. Acesso em: 2 oct. 2017.

ZIZEK, Slavoj. Repetir Lenin. Madrid: Akal, 2004. 